\title{
Anticentromere antibody in primary biliary cirrhosis
}

\author{
R. M. BERNSTEIN, M. E. CALLENDER, J. M. NEUBERGER, \\ G. R. V. HUGHES, AND ROGER WILLIAMS \\ From the Rheumatology Unit, Department of Medicine, Hammersmith Hospital, and the Liver Unit, King's \\ College Hospital, Denmark Hill, London
}

\begin{abstract}
SUMMARY An autoantibody specific for the centromere region of chromosomes and recently detected in the serum of patients with scleroderma was found in the serum of $10(9 \cdot 1 \%)$ of 110 consecutive patients presenting with primary biliary cirrhosis. It was found exclusively among those with scleroderma, giving a prevalence of $50 \%$ in that group, and all patients with telangiectasia or calcinosis had the antibody. It was not found in 80 patients with chronic active hepatitis, including the 'autoimmune' variety. The pathogenetic significance of anticentromere antibody is not yet established, but this study confirms its specificity for scleroderma in the context of primary biliary cirrhosis.
\end{abstract}

Scleroderma was first described in patients with liver disease by Milbradt in $1934,{ }^{1}$ and the reports of Murray-Lyon et al. ${ }^{2}$ and others ${ }^{34}$ later drew attention to its association with primary biliary cirrhosis (PBC). In a subsequent analysis of a large series of patients with $P B C$ we found the frequency of scleroderma to be $17 \% .^{5}$ Why scleroderma should occur in PBC and in only some patients is not known, but the scleroderma in PBC is usually mild and of the CREST (calcinosis, Raynaud's phenomenon, oesophageal dysmotility, sclerodactyly, telangiectasia) variety, though there have been some reports of diffuse scleroderma. ${ }^{56}$

Of recent interest has been the description of a serum antibody reacting with the centromere portion of chromosomes in tissue culture cells and found in patients with scleroderma, especially of the CREST type..$^{7-10}$ We have looked for anticentromere antibody in serum from 110 consecutive patients presenting with PBC, 20 of whom had scleroderma, and from 80 patients with other forms of liver disease, including the autoimmune variety of chronic active hepatitis $(\mathrm{CAH})$.

\section{Materials and methods}

The series comprised 110 consecutive patients with biopsy-proved PBC, of whom $97(88 \cdot 2 \%)$ were women and $13(11.8 \%)$ were men. Antimitochondrial antibody was present in $94(85.5 \%)$ patients, antinuclear antibody in $11(10 \%)$, and anti-

Accepted for publication 13, November 1981.

Correspondence to Dr Roger Williams, Liver Unit, King's College Hospital Medical School, Denmark Hill, London SE5 8RX. smooth-muscle antibody in $3(2 \cdot 7 \%)$. None had antibody to ribonucleoprotein, as found in mixed connective tissue disease, when tested by counterimmunoelectrophoresis.

Each patient was reviewed specifically for features of scleroderma by one clinician, and cutaneous scleroderma was found in $20(18.2 \%)$ patients. In 19 patients the changes were confined to the fingers and perioral skin, and in one there was proximal scleroderma involving the hands and arms. Thirteen of these patients had Raynaud's phenomenon; 4 had capillary telangiectasia of the fingers; 3 had calcinosis on radiographs of the hands; and 3 had dilatation and atony of the oesophagus on a barium swallow and meal examination. The patient with proximal scleroderma also had basal pulmonary fibrosis on a chest radiograph. Ten of the 20 patients with scleroderma also had the sicca syndrome, confirmed by an abnormal Schirmer's test of tear secretion. Of the 90 PBC patients without scleroderma 4 had Raynaud's phenomenon and 22 had the sicca syndrome.

A comparison group of 80 patients with biopsyproved CAH comprised $46(57.5 \%)$ men and 34 $(42.5 \%)$ women. Among the 50 patients whose serum was negative for hepatitis $B$ surface antigen ( $\mathrm{HBs} \mathrm{Ag}$ ) by radioimmunoassay one had scleroderma with an erosive arthritis, and antinuclear antibody was found in $33(66 \%)$, anti-smooth-muscle antibody in $29(58 \%)$, and antimitochondrial antibody in one (2\%). Among the $30 \mathrm{HBsAg}$-positive patients none had scleroderma, $4(13.3 \%)$ had antinuclear antibody, and $6(20 \%)$ had anti-smooth-muscle antibody. 
ANTICENTROMERE ANTIBODY

Serum samples stored at $-20^{\circ} \mathrm{C}$ were randomised and examined under code for anticentromere antibody by indirect immunofluoresence. The substrate was a cell line, HEp-2, originally derived from a human laryngeal carcinoma. Sera diluted 1:40 in PBS (phosphate-buffered saline, 0.01 M phosphate, 0.14 M sodium chloride, $\mathrm{pH} \mathrm{7.4)} \mathrm{were} \mathrm{incubated} \mathrm{at} \mathrm{room}$ temperature for 30 minutes on $\mathrm{HEp}-2$ cells adherent to glass slides (Antibodies Incorporated, Davis, California, USA). The slides were washed for 10 minutes in PBS and then incubated for 30 minutes with a fluorescein isothiocyanate conjugated goat antihuman IgG (Wellcome Laboratories). After another 10-minute wash the slides were mounted in $50 \%$ glycerol in PBS and examined at 500 times magnification. Anticentromere antibody was seen as discrete granular immunofluorescence on interphase nuclei with characteristic localisation on the metaphase plate of mitotic cells (Fig. 1).

\section{Results}

Anticentromere antibody was found in $10(9 \cdot 1 \%)$ of the 110 patients with $\mathrm{PBC}$. These 10 patients all had scleroderma, giving an antibody frequency of 10 $(50 \%)$ out of 20 in the scleroderma group, compared

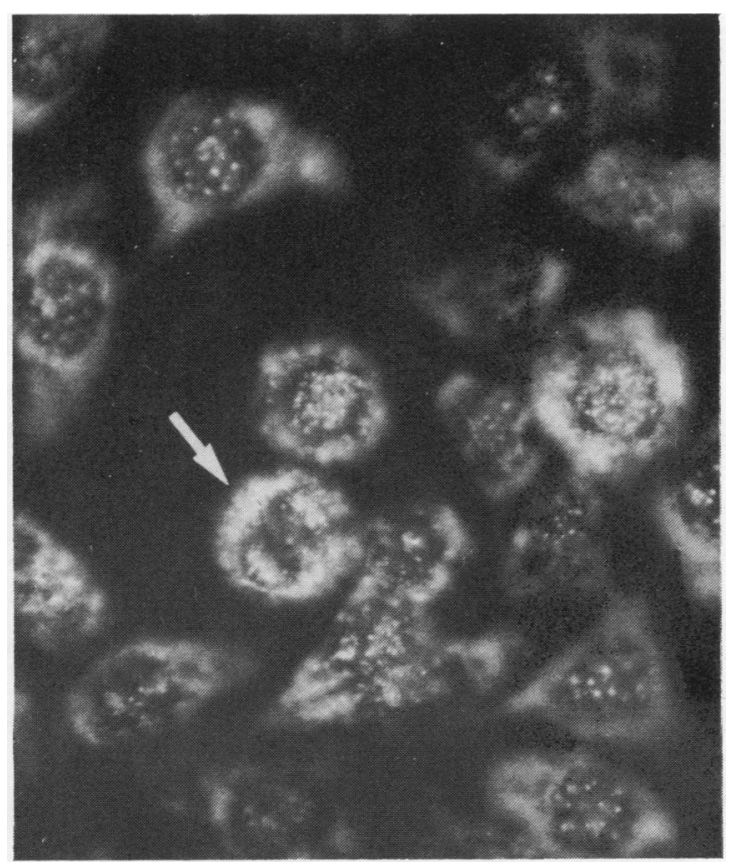

Fig. 1 Centromere staining in HEp-2 cells is seen as discrete granules in interphase cells and with characteristic localisation in the mitotic cell (arrow). Mitochondrial staining is present in the cytotplasm. $(\times 500)$.
Table 1 Anticentromere antibody in relation to clinical features of the CREST syndrome

\begin{tabular}{lll}
\hline & $\begin{array}{l}\text { Total } \\
\text { patients }\end{array}$ & $\begin{array}{l}\text { Anticentromere } \\
\text { antibody-positive }\end{array}$ \\
\hline $\begin{array}{l}\text { Raynaud's phenomenon } \\
\text { Scleroderma alone or (1 patient) } \\
\text { with oesophageal involvement }\end{array}$ & 4 & 0 \\
$\begin{array}{c}\text { Scleroderma with Raynaud's } \\
\text { phenomenon and (2 patients) } \\
\text { oesophageal involvement }\end{array}$ & 10 & 5 \\
$\begin{array}{c}\text { Scleroderma with telangiectasia } \\
\text { or calcinosis or both }\end{array}$ & 5 & 5 \\
\hline
\end{tabular}

with none out of 90 of the PBC patients without scleroderma ( $p<0.0001$, Fisher's exact test). Among the PBC patients with scleroderma the antibody was present in all 5 who had telangiectasia or calcinosis, in only 8 of the 13 with Raynaud's phenomenon, 5 of the 10 with sicca syndrome, and one of the 3 with oesophageal involvement. It was not found in the patient with proximal scleroderma and pulmonary involvement (Table 1).

The various specific features of the CREST syndrome were found more commonly in the group of patients with anticentromere antibody than in those without the antibody. In the former group there was one patient with 4 features of CREST, 4 patients with 3 features, and 5 patients with 2 features, whereas in the latter group there was one patient with 3 features of CREST, 5 with 2 features, and 4 with one feature.

Among the patients with PBC and scleroderma there was no significant difference between anticentromere antibody-positive and antibody-negative groups in terms of their mean age, sex ratio, titre of antimitochondrial antibody, or the severity of liver disease as judged by serum bilirubin level or liver histology.

Anticentromere antibody was not found in any of the 80 patients with $\mathrm{CAH}$ either of the 'autoimmune' HBsAg-negative type or of the HBsAg-positive type.

\section{Discussion}

This is the first study showing that anticentromere antibody is highly specific for scleroderma even among patients presenting with PBC. Anticentromere antibody was found only in patients with scleroderma and was more common in those with additional features of the CREST syndrome, particularly calcinosis and telangiectasia. This may explain why the prevalence of the antibody in patients in this study differs from that in previous reports. The patients in whom Fritzler et al. ${ }^{9}$ reported a $98 \%$ prevalence of anticentromere antibody had all 5 features of CREST, and those in whom Moroi et al. ${ }^{7}$ reported an $87.5 \%$ prevalence of the antibody had either 4 or 5 features. However, in our 20 patients, of whom 10 
$(50 \%)$ had anticentromere antibody, 4 or fewer features of CREST were found.

Fritzler et al. ${ }^{9}$ found that in patients with various rheumatic disorders anticentromere antibody was present only among those with Raynaud's phenomenon. Furthermore they reported anticentromere antibody in $21 \%$ of patients with isolated Raynaud's disease. This restriction to Raynaud's phenomenon was not confirmed in the present study. Two of the 10 patients with anticentromere antibody did not have Raynaud's phenomenon, and anticentromere antibody was not found in any of the 4 patients who had Raynaud's phenomenon without scleroderma. As in Fritzler's study we were unable to find any association between the sicca syndrome and anticentromere antibody. Anticentromere antibody was not found in the one patient in this study with diffuse scleroderma, and this is in agreement with the relatively low frequency of anticentromere antibody of $8-12.5 \%$ reported by others in diffuse scleroderma. ${ }^{7-9}$

It is of interest that antinuclear antibody was detected by indirect immunofluorescence on organ sections in only one of the 10 sera in which anticentromere antibody was found using HEp-2 tissue culture cells. This superior sensitivity of tissue culture cells for the detection of anticentromere antibody was reported by Tan et al., ${ }^{8}$ who found antinuclear staining of mouse kidney sections with only 6 of the 14 sera that gave anticentromere staining on HEp-2 cells. In previous studies with a variety of organ sections as substrate for immunofluorescence antibody has been detected in $40-60 \%$ of patients with scleroderma, ${ }^{112}$ but with tissue culture cells the incidence has exceeded $90 \% .^{7-9}$ This increased detection of antinuclear antibodies is largely accounted for by the anticentromere antibody, which is found more readily with rapidly dividing cells, since they contain larger quantities of certain nuclear antigens. Furthermore the frequent mitotic figures reveal the characteristic pattern of anticentromere staining in metaphase cells.

It has been suggested that anticentromere antibody may be the serum factor in scleroderma patients which can cause breaks in chromosomes. ${ }^{13} 14$ Although there is no evidence that chromosome damage is responsible for the skin changes in scleroderma, the finding of anticentromere antibody in 3 patients with isolated Raynaud's phenomenon in whom clinical scleroderma later developed ${ }^{9}$ suggests that the antibody is present very early in the disease. Another serum factor in patients with scleroderma produces damage to human endothelial cells and fib- roblasts in tissue culture,,$^{15}$ but this elutes from chromatography columns with the albumin fraction and is probably not an antibody.

Since anticentromere antibody was not found in any of the patients with CAH, many of whom had antinuclear and other autoantibodies, it cannot be regarded as a nonspecific feature of 'autoimmune disease.' Rather it seems to be a highly specific marker of scleroderma even in the context of PBC. This study also indicates an immunological similarity between the mild scleroderma detected in patients with $\mathrm{PBC}$ and scleroderma occurring as a primary disease in its classical forms.

We are grateful to Dr D. E. H. Tee, Immunology Department, King's College Hospital, for serum autoantibody results using organ sections, and to Mrs Yvette S white for HBsAg testing.

\section{References}

1 Milbradt W. Atypische diffuse sklerodermia mit Oslerschem syndrom und leberstörung. Dermatol Monatsschr 1934; 99: 973-9.

${ }^{2}$ Murray-Lyon I M, Thompson R P H, Ansell I D, Williams, R. Scleroderma and primary biliary cirrhosis. Br Med J 1970; iii: 258-9.

${ }^{3}$ Reynolds T B, Denison E K, Frankl H D, Lieberman F L, Peters R L. Primary biliary cirrhosis with scleroderma, Raynaud's phenomena, and telangiectasia. Am J Med 1971; 67: 302-12.

4 August P J. Primary biliary cirrhosis and scleroderma. Proc $R$ Soc Med 1974; 67: 1238-9.

5 Clarke A K, Galbraith R M, Hamilton E B D, Williams R. Rheumatic disorders in primary biliary cirrhosis. Ann Rheum Dis 1978; 37: 42-7.

- O'Brien S T, Eddy W M, Krawitt E L. Primary biliary cirrhosis associated with scleroderma. Gastroenterology 1972; 62: 118-21.

? Moroi Y, Peebles C, Fritzler M J, Steigerwald J, Tan E M. Autoantibody to centromere (kinetochore) in scleroderma sera. Proc Natl Acad Sci USA 1980; 77: 1627-31.

- Tan E M, Rodnan G P, Garcia I, Moroi Y, Fritzler M J, Peebles C. Diversity of antinuclear antibodies in progressive systemic sclerosis. Arthritis Rheum 1980; 23: 617-25.

9 Fritzler M J, Kinsella T D, Garbutt E. The CREST syndrome: a distinct serologic entity with anticentromere antibodies. $\mathrm{Am} \mathrm{J}$ Med 1980; 69: 520-6.

10 Bernstein R M, Steigerwald J C, Tan E M. Association of antinuclear and antinucleolar antibodies in progressive systemic sclerosis. Clin Exp Immunol 1982; 48: 43-51.

"Beck J S, Anderson J, Gray K G, Rowell N R. Antinuclear and precipitating autoantibodies in progressive systemic sclerosis. Lancet 1963; ii: 1188-90.

12 Rothfield N F, Rodnan G P. Serum antinuclear antibodies in systemic sclerosis (scleroderma). Arthritis Rheum 1968; 11: 607-17.

13 Housset E, Emerit I, Baulon A. Anomalies chromosomiques dans la sclérodermie généralisée. Une étude de dix malades. $C R$ Acad Sci (D) Paris 1969; 269: 413-6.

14 Pan S F, Rodnan G P, Wald N. Chromosomal abnormalities in progressive systemic sclerosis (scleroderma). Arthritis Rheum 1971; 14: 407-8.

15 Kahaleh M B, Sherer G K, Le Roy E C. Endothelial injury in scleroderma.J Exp Med 1979; 149: 1326-35. 